\title{
Analisis Kritik Sastra Menggunakan Pendekatan Pragmatik Pada Antologi Cerpen Karya Hasan Al Banna
}

\author{
Ramadhan Saleh Lubis ${ }^{1}$, Yolandita Octavianty Sipahutar ${ }^{2}$, Jesika Anasthasia Siregar ${ }^{3}$, \\ Asni Sumarni Saragih ${ }^{4}$, Gugun Kristina Silalahi ${ }^{5}$ \\ E-mail: yolanditaoctavianty@gmail.com \\ Universitas Prima Indonesia
}

\begin{abstract}
ABSTRAK
Penelitian ini bertujuan untuk menyampaikan tujuan tertentu kepada pembaca. Tujuan tersebut berupa tujuan efek estetika, nilai agama, nilai moral, nilai sosial, dan budaya dalam antologi cerpen karya Hasan Al Banna. Sumber data dalam penelitian ini adalah kumpulan cerpen karya Hasan Al Banna. Data dalam penelitian ini adalah tujuan kepada pembaca melalui nilia-nilai menggunakan pendekatan pragmatik. Metode yang digunakan dalam penelitian ini adalah metode deskriptif. Instumen dalam penelitian ini yang dipakai adalah jurnal yang berkaitan dengan penelitian. Teknik analisis datanya adalah dengan cara membaca teliti, menghayati, memahami, kemudian menganalisis data sesuai dengan aspek yang dikaji dengan cara sistematis dan terperinci. Hasil yang diperoleh terdapat gambaran efek kesenangan, kesedihan, dan efek estetika. Serta terdapatnya nilai-nilai yang dibaca oleh sipembaca seperti nilai agama, sosial, budaya, dan agama.
\end{abstract}

Kata Kunci: Antologi Cerpen, Pendekatan Pragmatik

\section{PENDAHULUAN}

Karya sastra telah banyak dipelajari dalam dunia pendidikan dan bahkan telah melekat untuk memenuhi kebutuhan manusia sesuai dengan kehidupan masing-masing. Karya merupakan sesuatu hasil khayalan ataupun pemikiran seseorang yang dapat dipresentasikan. Sedangkan Sastra merupakan sebuah seni yang indah. Maka dari itu karya sastra dapat diartikan dengan suatu khayalan manusia yang kreatif dan dapat menghasilakan suatu wujud keindahan. Keindahan itu dapat diperoleh manusia dengan cara berpikir luas tanpa ada batasan dan dapat 
berkarya secara bebas sesuai dengan khayalan manusia itu sendiri. Menurut Danamo dalam (Sitinjak, 2018), karya sastra ada untuk dimanfaatkan masyarakat dalam kehidupan dan mampu memberikan pengaruh besar kepada kehidupan masyarakat. Karya sastra juga dapat diartikan sebuah karangan dalam bentuk kata yang di dalam karangan tersebut terdapat nilai-nilai yang sangat berguna bagi pembaca.

Didalam dunia pendidikan bahkan dalam kehidupan masyarakat karya sastra sangat berfungsi seperti sebagai hiburan, mendidik, memberikan keindahan, serta memberikan ajaran ajaran mengenai agama yang dapat ditiru atau diteladani bagi pembaca serta penikmat karya sastra tersebut. Berdasarkan bentuk, karya sastra dapat dibagi menjadi tiga. Pertama puisi, yang dimana puisi terbagi menjadi empat jenis yakni puisi lama, baru, bebas dan kontemporer. Kedua drama dan yang ketiga ialah prosa. Prosa memiliki dua jenis yakni prosa lama dan prosa baru. Bentuk-bentuk prosa lama yaitu hikayat, sejarah, kisah, dongeng, sedangkan jenis prosa baru yaitu roman, novel, cerpen, riwayat, kritik, resensi, serta esai. Pada penelitian ini, peneliti akan membahas antologi cerpen karya Hasan Al Banna yang di dalam cerpen tersebut terdapat nilainilai berguna bagi pembaca dengan menggunakan sudut pandang pendekatan pragmatik. Cerpen adalah suatu bentuk cerita sederhana yang menguraikan kalimat, sehingga berbentuk paragraf yang berisikan permasalahan-permasalah atau konflik serta penyelesaian dalam cerita. Cerpen juga merupakan cerita yang banyak diterbitkan pada media seperti media online, koran, majalah, dan bahkan cerpen juga sudah dijadikan sebuah buku antalogi cerpen karena, cerpen memiliki kisah permasalahan yang tidak mendalam dan mengisahkan cerita yang sederhana. Selain itu cerita pendek juga memiliki ciri yang berkesan dari pengalaman pribadi penulis. Sehingga cerpen sangat banyak diminati oleh banyak kalangan anak-anak, remaja, dan bahkan dewasa. Hal ini sejalan dengan pemikiran (Munauwarah, 2014), cerpen adalah prosa baru yang di dalamnya menceritakan suatu kehidupan berisikan konflik dan tidak adanya perubahan nasib pada tokoh dalam (Jus'amma, Andi, Nurqalbi; hal 9).

Adapun pengertian pendekatan pragmatik dalam karya sastra adalah pendekatan kritik sastra yang melihat karya sastra bertujuan untuk menginformaikan sekaligus memberikan pengajaran sesuatu hal kepada pembaca. Sesuatu hal yang dimaksud ialah adanya kesan bagi pembaca baik berupa pendidikan, estetika, religius, sosial dan lainnya. Hal tersebut didukung oleh pendapat Wahyudi dalam (TriGumono, Abednego, 2017) pendekatan pragmatik merupakan pendekatan kajian sastra yang memiliki peran utamanya kepada pembaca dalam menerima, 
menghayati, dan memahami karya sastra. Kesan yang didapat pembaca, mengandung nilai-nilai yang terkandung dalam pendekatan pragmatik seperti nilai dari segi estetika, sosial, dari religius, moral, dan kesan pembaca lainnya. Pentingnya nilai-nilai dalam kesan pembaca dengan menggunakan pendekatan pragmatik karena akhir-akhir ini telah menurunnya akhlak dan moral seseorang yang membuat kericuan atau keributan serta kurangnya kesadarnya akan nilai-nilai positif dalam kehidupan. Adapun untuk pendidikan yang telah diarahkan membentuk pribadi

yang cerdas akan tetapi melupakan aspek aspek religius, etika, moral yang dapat membentuk karakter anak bangsa.

Dalam antologi cerita pendek karya Hasan Al Banna peneliti meneliti cerita pendek karya Hasan Al Banna sebanyak sepuluh cerita pendek yang dimuat diberbagai media seperti media onlie, Koran, serta majalah pada tahun 2006, 2007, 2008, dan 2009 yang menganalisis kritik sastra dengan menggunakan pendektan pragmatik. Kumpulan cerita pendek karya Hasan Al Banna dengan menggunakan pendekatan pragmatik ini diangkat peneliti karena memiliki kesan bagi pembacanya dimana pembaca dapat menikmati serta mendapat pelajaran dari berbagai cerita karya Hasan Al Banna tersebut. Serta membentuk nilai-nilai karakter yang didapat pembaca setelah membaca kumpulan cerita pendek karya Hasan Albana. Selain itu peneliti mengambil cerpen karya Hasan Albana karena Hasan Al Banna adalah sorang mujahid dakwah, peletak dasar gerakan islam serta pemimpin ikhwanul muslim atau disebut dengan persaudaraan muslim yang berprestasi sejak dini dan selalu memiliki tekat, ketekun dalam segal hal apapun yang dilakukannya. Maka dari itu peneliti tertarik untuk meneliti beberapa cerpen karya Hasan Al Banna dengan judul Analisis Kritik Sastra menggunakan Pendekatan Pragmatik pada Antologi Cerpen Karya Hasan Al Banna.

\section{KAJIAN TEORI}

\section{a. Kritik}

Kritik sastra tersebut dapat diartikan ialah sebagai salah satu objek studi sastra (cabang ilmu sastra) yang melakukan analisis, penafsiran, serta juga penilaian terhadap teks sastra.

\section{b. Pendekatan Pragmatik}

Pendekatan pragmatik adalah pendekatan yang memandang karya sastra sebagai sarana untuk menyampaikan tujuan tertentu kepada pembaca. Dalam hal ini tujuan tersebut dapat 
berupa tujuan pendidikan, moral, politik, agama, ataupun tujuan yang lain. Atau pendekatan pragmatik adalah pendekatan yang memandang karya sastra sebagai sesuatu hal yang dibuat atau diciptakan untuk mencapai atau menyampaikan efek-efek tertentu pada penikmat karya sastra, baik berupa efek kesenangan, estetika atau efek pengajaran moral, agama atau pendidikan dan efek-efek lainnya.

\section{c. Antologi Cerpen}

Antologi merupakan buku berisi kumpulan karya bisa satu atau beberapa penulis. Antologi cerpen berarti buku yang isinya kumpulan karya cerpen dari seorang atau beberapa penulis.

\section{METODELOGI PENELITIAN}

Pendekatan penelitian ini, menggunakan pendekatan kualitatif. Menurut Bodgan dan Biklen (199: 221-22), kualitatif adalah pendekatan menggambarkan sesuatu hal seacara jelas berupa tulisan maupun lisan serta perilaku orang yang diamati dalam (Rahmat Pupu seuful, 2009: hal 2). Pendekatan kualitatif ini sering digunakan oleh peneliti untuk mengkaji sebuah karya satra. Jenis penelitian ini menggunakan konten analisis. Penelitian ini merupakan bentuk analisis isi yang pembahasannya dapat mengasilkan informasi, yang bahannya terdiri dari buku. Konten penelitian analisis ini adalah antologi cerpen karya Hasan al Banna. Menurut Zulkifli A.M data merupakan suatu kumpulan informasi yang memberikan keterangan secara fakta yang masih dapat dikelola. Mencari kritik sastra melalui nila-nilai menggunakan pendekatan pragmatik. Sumber Data Primer Sumber data primer atau sumber utama dari penelitian ini ialah menggunakan kumpulan cerpen Hasan Al Banna.

Sumber data sekunder atau sumber data yang kedua dalam penelitian ini adalah menggunakan sumber-sumber lain yang sudah dipercaya seperti refrensi jurnal, buku yang mendukung analisis penelitian ini. Teknik pengumpulan data dalam penelitian ini menggunakan teknik Babat, yang dilakukan dengan cara membaca keseluruhan cerpen Hasan Al Banna yang ada dalam penelitian ini. Teknik analisis data dilakukan dengan menganalisis isi antologi cerpen karya Hasan Al Banna melalui nilai-nilai yang terdapat dalam pendekatan pragmatik. Data ini dikumpulka oleh peneliti dengan menggunakan langkah-langkah yaitu pertama Membaca secara teliti antologi cerpen karya Hasan Al Banna untuk mencari nila-nilai yang terdapat dalam pendekatan pragmatik pada cerpen tersebut, dan yang kedua Menetapkan dan menganalisis data 
sesuai dengan aspek yang dikaji Pembahasan data ini yang dilakukan peneliti secara sistematis, terperinci, untuk mempermudah peneliti memahami nilai- nilai pragmatik di dalam antologi cerpen karya Hasan Al Banna.

\section{PEMBAHASAN DAN HASIL.}

\section{a) Efek Estetis}

Estetis merupakan keindahan dari karya sastra yang dapat menghidupkan sebuah cerita menjadi lebih menarik melalui dari kata-kata atau kalimat seperti majas, kata-kata mutiara, dan juga pribahasa.

1. Keindahan cerpen ditunjukkan pada kutipan: "Abit godang seperti teko berkarat yang mengguyurkan kopi pahit ke gelas kemenangan." (Hasan Al Banna; parompa sadun kiriman ibu. 2006; parg.10)

Kutipan di atas menunjukkan majas asosiasi di mana asosiasi ialah membandingkan dua objek yang berbeda tetapi dianggap sama dengan memberi kata sambung dengan kata bak, bagaikan, seperti. Pada kalimat di atas terdapat seperti yang mengartikan abit godang seperti teko yang rusak menuangkan kepedihan dalam kemenangan.

2. Tapi harapan itu pun padam bagai bangkai bara yang hitam" (Hasan Al Banna; parompa sadun kiriman ibu. 2006; parg.23)

Kutipan di atas menunjukkan peribahasa atau kata/ kalimat yang disusun untuk mengiaskan maksud. Yang memiliki arti harapan itu telah mati bagai bangkai yang terbakar menjadi arang atau habis dan lenyap.

3. Alah, suaraku angka merah, kawan" (Hasan Al Banna; Bob Marley. 2006; parg.4)

Kutipan tersebut mengandung keindahan gaya bahasa melalui majas atau gaya bahasa metafora yang mengartikan suaranya memiliki nilai yang rendah atau bisa disebut dengan tidak sempurna atau jelek.

4. Isak tangis pun timbul-tenggelam" (Hasan Al Banna; Bob Marley. 2006; parg.8)

Kutipan tersebut mengandung keindahan majas metafora yang mengartikan suara tangis ada dan hilang. 
5. "Sebenarnya, kurang enak badan Mak Odah tadi pagi." (Hasan Al Banna; Hanya angin yang terpahat dirahang pintu. 2006; parg.2)

Kalimat di atas menunjukkan majas metafora yang ditandai dengan kalimat "kurang enak badan" yang mengandung arti bahwa ia sakit.

6. "Hidup umpama main ular tangga" (Hasan Al Banna; Rabiah. 2005; parg 2).

Kutipan diatas merupakan Nilai Estetis yang merupakan sebuah perumpamaan hidup seperti main ular tangga kadang di atas kadang juga kalau sedang mengalami kesulitan atau nasib kurang beruntung akan turun.

7. "Hmm, Zulaiha adalah kepalan baja, atau pualam siksa?" (Hasan Al Banna; Sampan Zulaiha. 2006; parg 27).

Pada penggalan kalimat di atas termasuk kedalam metafora yang mengartikan zulaiha orang yang sabar, tidak pernah mengeluh dan selalu kuat dalam kehidupannya.

\section{b) Efek Kebermanfaatan}

Efek kebermanfaatan adalah cerita yang dapat diambil menjadi sebuah pesan dan kesan dan dapat bermanfaat bagi pembaca seperti nilai-nilai yang terkandung dalam cerita.

\section{Nilai Agama}

Nilai agama adalah sesuatu yang berhubungan dengan kitab suci, nilai-nilai kehidupan yang mendasari agama atau kepercayaan manusia.

a. "Di Madrasah tersebut, para murid setingkat SD belajar mengaji dan ilmu agama, dituntun guru-guru belia tamatan pesantren tersohor, Purba Baru-Mandailing Natal." (Hasan Al-Banna; Pasar Jongjong. 2006; paragraf 7)

Kutipan Kalimat di atas menggambarkan nilai agama yang terdapat pada pasar jongjong. Nilai agama yang terdapat pada kutipan cerita diatas dimana murid murid yang di Madrasah diajarkan untuk mengkaji nilai nilai agama dan diajarakan untuk mengaji. 
b. Jangan sepele kelien, pandai mengaji dia. Sudah itu, kalau ada warga yang meninggal, Bob Marley giat mengurus keperluan kifayah jenazah, khususnya menyiapkan galian kuburan. Terus, biar tau saja, hampir tak pernah absen dia ikut tahlilan, genap tiga malam.” (Hasan Al Banna; Kematian Bob Marley. 2006;parg.16)

Kutipan di atas menggambarkan nilai agama di mana seseorang yang menunjukkan pandai mengaji, giat mengurus keperluan kifayah jenazah, dan tak pernah dia takut tahilan, genap tiga malam.

c. "Inilah jalan hidupku, Bu. Tapi aku tetap percaya bahwa ini adalah jalan terbaik yang di berikan Allah untukku, untuk kita”. (Hasan Al Banna; rabiah. 2005; paragraph 3)

Kutipan di atas menunjukan nilai agama yang terdapat pada kata" Jalan terbaik di berikaan Allah untukku", kata tersebut bermakna menyapaikan kepercayaan agama kepada Allahnya

d. "Ya, kebiasaan Haji Sudung Sembahyang Jemaah di kampung tak bisa ia tinggalkan." (Hasan Al Banna; Rumah Amang Boru: parg.16)

Kutipan di atas menunjukkan nilai agama yang bahwasanya Haji Sudung tetap menjalankan ibadahnya dan mengingat Allah.

\section{Nilai Sosial}

Nilai sosial merupakan nilai yang ada hubungannya dengan masalah sosial atau interaksi dengan manusia. Terdapat nilai sosial dalam kumpulan cerpen Hasan Al Banna ialah:

a. "Dengan senang hati ia sambut kerabat dan tetangga dekat. Para tamu silih berganti datang dan pulang. Mereka mengucapkan kata selamat, mengayunkan salam, memberi pelukan, dan berebut mencium pipi si buah hati. Di antara mereka ada yang meninggalkan bingkisan di sisi Uli. Sebagian lagi menyelipkan amplop yang berisi uang ke tangan Lamrina." (Hasan Al Banna; Parompa Sadun Kiriman Ibu. 2006; parg 3).

Pada kutipan cerpen di atas terdapat nilai sosial yang diambil bahwa perilaku sopan santun, dam rasa peduli dengan saling memberi anatar sesama dan mengucapkan selamat kepada 
nya dan ibunya salah satu menggambarkan bahwa para tetangga dan kerabatnya saling menghargai.

b. "Bersebab sudah terlampau lama aku pergi bertandang ke rumah-rumah yang lain; menikmati tuturan ramah pemiliknya, menikmati tawaran sarapan yang selalu berbeda, menikmati hidangan makan siang yang memanjakan selera, menikmati makanan senja yang bermacam adanya, menikmati suguhan minuman yang beragam rasa-warnanya, menikmati cerita-cerita beraneka kiranya, juga menikmati tidur yang paling nyaman tentunya.” (Hasan Al Banna; Monolog Lelaki Merindukan Pulang. 2006)

Pada kutipan cerpen di atas menunjukkan nilai sosial bahwa seseorang pergi kerumah orang lain dan selalu dilayani dengan baik oleh orang yang berada di rumah tersebut dengan ramah ia menawarkan sarapan, hidangan makan siang, minumnya dan juga tidur di tempat yang paling nyaman. Jelas terlihat dari kalimat tersebut adanya rasa bersosialisasi antar sesama.

c. "Mak Odah rajin meneguri para tetanga yang beriring pulang dari laut." (Hasan Al Banna; Hanya angina yang terpahat dirahang pintu. 2006; parg.6)

Jelas terlihat pada kalimat "meneguri tetangganya." Di situ terdapat nilai sosial. Yang di mana mak odah memiliki nilai bersosialisai dengan cara berinteraksi antar sesama seperti menyapa para tetangganya dengan baik.

d. "Lalu datang Bu Ifah, tetangga kita baik hati itu menawarkan pekerjaan. "Ibu punyak saudara yang bisa membantumu," katanya” (Hasan Al Banna; Rabiah. 2005; paragraph 3)

Kalimat di atas termasuk ke dalam nilai sosial yang mengandung makna bahwa tetangganya berniat baik untuk menawarkan pekerjaan dengannya. Jelas terlihat adanya hubungan interaksi baik dengan tetangganya.

\section{Nilai budaya}

Nilai budaya merupakan nilai kebiasaan atau adat istiadat masyarakat. Terdapat nilai budaya pada antologi cerpen tersebut ialah: 
a. "Ia pun terkenang pula dengan riuh suka-cita acara manjagit parompa, acara adat Angkola menyambut kelahiran anak sulung. Pada acara itu diundanglah parompa oleh ompung - nenek dari pihak perempuan / ke-cucunya. Jika penyerahannya secara adat, cari kambing syarat yang penting. Pemuka adat juga harus hadir. Tapi jika hanya acara sederhana, cukup menyembelih ayam. Undangan terdiri dari kerabat dan tetangga." (Hasan Al Banna; Parompa Sadun Kiriman Ibu. 2006; parg 7)

Pada kutipan cerpen di atas terdapat nilai budaya kebiasaan orang batak yang di mana suku batak menyambut kelahiran anak sulung dengan diundang opung atau nenek dari pihak perempuan ke cucunya dan penyerahannya paling penting adanya daging kambing serta pembuka adat juga harus hadir. Jika acaranya sederhana cukup dengan adanya daging ayam serta undangan dari kerabat dan tetangga.

b. "Berdasarkan syarat adat, istri pantang meminta cerai" (Hasan Al Banna; Tiurmaida. 2006; parg.7)

Kalimat di atas termasuk nilai kebudayaan atau kebiasaan adat di mana jelas terlihat di kalimat ingin meminta cerai, yang mengartikan perbuatan terlarang.

\section{Nilai Moral}

Nilai moral adalah segala sesuatu yang mengajarkan baik buruknya tingkah laku seseorang atau budi pekerti seseorang dengan sesamanya.

a. "Mensyukuri rezeki itu perbuatan baik. Dan menikmati hidangan ini adalah salah satu perwujudan rasa syukur. Maka, silakan dinikmati” (Hasan Al Banna; Monolog Lelaki Merindukan Pulang. 2006)

Kalimat di atas menunjukkan nilai moral yang baik di mana ia selalu bersyukur atas segala nikmat yang sudah diberikan kepadanya. Lewat rasa syukur pembaca telah tahu bahwa dia seseorang yang memiliki moral dengan baik.

b. "Butir-butir harapan menggelinding juga dari terjal hati Mak Odah: Azmi kelak pengganti kepala keluarga. Melindungi Mak dan Lastri, bahkan kelak menjadi penabung 
lumbung ekonomi keluarga. Tapi jangankan berkirim ringgit, segeliat surat pun tak pernah menyelip ke ketiak pintu. Azmi tetap saja berkabar kabur. Lalu simpang-siur kabar yang menyebar: Azmi mati, Azmi sudah menikah, atau Azmi tertangkap Polis Diraja Malaysia dan kini di penjara, seperti menyedot-memuntah semangat hidup Mak Odah." (Hasan Al Banna; Hanya Angin yang Terpahat di Rahang Pintu. 2006; parg. 26)

Kalimat tersebut menunjukkan nilai moral yang tidak baik di mana perilaku Azmi tidak sesuai dengan apa yang diharapkan oleh ibunya dan membuat hati ibunya sakit.

c. "Aku berniat meringankan beban Ibu." (Hasan Al Banna; Rabiah. 2005; paragraph 3)

Kalimat di atas termasuk nilai moral yang baik di mana ia berniat baik untuk tidak menyusahkan ibunya.

d. "hah, mengapa kau tak membiarkan saja anak sialan ini hanyut, dempol! Biar mati sekalian" (Hasan AL Banna; sampan zulaiha. 2006; paragraph 11)

Kutipan di atas menjukkan bahwa nilai moral yang buruk yang ingin menghanyutkan dan membiarkan mati zulaiha.

e. "Ia himpun serpihan kepercayaan Отри Gabe yang berantakan. Dan ya, berhasil. Ompu Gabe perlahan bangkit, membentuk grup baru, serta menampung kembali pemain dan pemusik grup lama." (Hasan Al Banna; Ceracau Oтри Gabe. 2007; parg. 12)

Kalimat di atas termasuk nilai moral yang baik. Di mana seseorang membangkitkan kembali rasa kepercayaan orang yang sudah berantakan menjadi bangkit kembali.

f. "Haji sudung tak menyangkal. Apa yang dikatakan menantunya itu kenyataan. Sepeninggal istrinya, bou Risda, sebidang sawah miliknya raib dijual keluarga sang istri. Konon, Maisa ikut andil. Lantas, rasa segan bakal diurus menantu bagi Haji Sudung untuk segera menghuni rumah Marsan. "(Hasan Al Banna; Rumah Amang Boru: parg. 8)

Kalimat di atas menunjukkan nilai moral yang baik menghormati keputusan orang lain. Walaupun Haji Sudung tidak menyukai keputusan menantunya akan tetapi ia menerima dengan alasan yang bisa di terima. 
g. "Amang Boru sudah uzur pa dan semua orang bakal mati. Kini kita harus memikirkan yang ada di depan. Masa depan keluarga kita, anak-anak kita." (Hasan Al Banna; Rumah Amang Boru: parg. 26) "Besok kita antar Amangboru ke panti jompo!” tegas Risa. (Hasan Al Banna; Rumah Amang Boru: parg. 27)

Kutipan pada paragraph di atas adalah termasuk ke dalam moral yang tidak baik. Tindakan yang dilakukan Risda kepada amang boru sungguh tidak pantas dilakukan baik dalam

omongan Risda yang mengatakan amangboru sudah uzur dan semua orang bakal mati serta perilaku Risa yang akan membuat Amang boru tinggal di panti jompo.

\section{Hasil}

Data penelitian ini adalah kajian dari pragmatik dalam kumpulan cerpen Hasan Al Banna. Setelah dikaji peneliti cerpen ini mengandung suatu efek bagi pembaca serta nilai-nilai yang terkandung dalam cerita. Diantaranya; efek kesenangan, efek kesedihan, efek estetis, efek kebermanfaatan. Efek kebermanfaatan seperti nilai agama, nilai sosial, nilai budaya, dan moral.

Efek Estetis terdiri atas 7 data dengan berbagai macam keindahan seperti majas asosiasi, pribahasa dan metafora.

$>$ Efek Kebermanfaatan yang terdiri atas:

a. Nilai Agama terdiri atas 4 data dalam bentuk rasa syukur terhadap Tuhan yang Maha Esa, mengajarkan agar selalu beribadah dengan baik dan tekun, memiliki rasa kepercayaan atas hidup yang diberikan oleh Tuhan yang Maha Esa, dan selalu mengingat untuk menjalankan ibdahnya kepada Tuhan.

b. Nilai Sosial terdiri atas 4 data dalam bentuk menegur tetangganya, berniat baik menawarkan pekerjaan baik untuk tetangganya, saling memperdulikan tetangga dengan bentuk rasa saling memberi, dan masih memiliki hati antar sesama untuk saling memberi terhadap tetangga walau baru dikenal

c. Nilai Budaya terdiri atas 2 data dalam bentuk acara budaya batak untuk menyambut kelahiran serta memberi nama kepada anak sulungnya dan kebiasaan orang yang beragama jika sudah menikah tidak boleh bercerai.

d. Nilai Moral terdiri atas 7 data dalam bentuk selalu bersyukur, perilaku yang tidak sesuai dengan apa yang diharapkan ibunya, berniat baik untuk tidak menyusahkan 
ibunya, berbuat tidak baik untuk memiliki niat membunuh seseorang, membangkitkan seseorang dari rasa putus asa nya, menghormati keputusan orang lain, serta berbicara dan memiliki niat yang tidak baik.

\section{KESIMPULAN DAN SARAN}

\section{Kesimpulan}

Kajian pragmatik merupakan kajian yang menganalisis nilai-nilai sosial, agama, kebudayaan, pendidikan, moral dan mengandung efek kesenangan, kesedihan, dan efek estetis terhadap karya sastra. Antologi pada cerpen ini memiliki karakter dan alur cerita yang berbeda-beda. Pada setiap cerpen menggambarkan beragam nilai-nilai tang terkandung didalamnya. Berdasarakan hasil analisis pragmatik dapat disimpulkan bahwa antologi cerpen karya hasan merupakan suatu karya yang baik dan bermutu. Cerpen ini dapat memberikan efek baik dan buruk bagi si pembaca. Cerpen ini tidak hanya menggambarkan suatu nilai kebaikan tetapi juga terdapat nilai yang buruk, salah satu contoh yaitu tindakan kekerasan pada cerpen yang berjudul "RABIAH".

Cerpen ini cocok dibaca pada kalangan jenjang SMA dan juga perguruan tinggi. Dalam antologi cerpen ini banyak mengangkat nilai kebudayaan khusunya pada kebudayaan batak dan nilai pendidikan. Cerpen ini sangat cocok dibaca untuk kalangan milenial. Bahkan pada cantologi cerpen Hasan Albanna memiliki alur cerita yuang mudah dipahami dan mengandung isi cerita yang memiliki nilai kemanusiaaan yang menggunakan bahasa yang sederhana dan mufah dipahami sehingga para pembaca tertarik untuk membaca dan mudah memahami setiap antologi cerpen yang mengandung keindahan dan, kejelasan tema, alur, bahasa, watak, latar dan sudut pandang yang menjurus pada penekanan pragmatic.

\section{Saran}

Dengan membaca antologi cerpen karya Hasan Albanna pembaca dapat lebih mahir dalam menganalisis karya sastra dengan menggunakan kajian pragmatik. Penulis mengharapkan saran dan kririk dari para pembaca untuk penyempurnaan makalahi ini. 


\section{DAFTAR PUSTAKA}

Prastowo, Andi. 2014. Memahami Metode-Metode Penelitian. Yogyakarta: Ar-Ruzz Media

Setiyadi, Bambang Ag. 2006. Metode Penelitian untuk Pengajaran Bahasa Asing Pendekatan Kualitatif dan Kuantitatif. Yogyakarta: Graha Ilmu

Khayati, Iga Noor. 2017. "Kritik Pragmatik pada Cerpen Pengemis dan Shalawat Badar Karya Ahmad Tohari" Diakses dari E-jurnal (https://www.academia.edu/34748233/KRITIK_SASTRA_PENDEKATAN_PRAGMAT IK_CERPEN_PENGEMIS_DAN_SHALAWAT_BADAR)

Novitasari, Desi. 2018. “Analisis Pragmatis Novel Biru Darah Gadisku Karya Darto Singo Dan Aplikasinya Dalam Pembelajaran Sastra Di SMA” Jurnal Skripsi

Gumono, Tri Abednego. 2017. “Analisis Film Denias dengan Pendekatan Pragmatik” E-journal of language, Literature, Culture, and Education Polyglot Vol.13 No.1, diakses melalui journal online.

Unknow. Taman Sastra Raudah Jambak (online) diakses dari (mraudahjambak.blogspot.com/2016/03/cerpen-hasan-al-banna.html?m=1) dikunjungi Jumat, 06 Maret 2020

Indriani, sri. 2015. Analisis Sastra dengan Pendekatan Pragmatik (online) diakses dari (https://www.google.com/amp/s/lotusfeet16.wordpress.com/2015/06/18/analisis-sastradengan-pendekatan-pragmatik/amp/) dikunjungi Rabu, 15 April 2020.

Listanto, Kokoh Dwiko. 2017. 12 Nilai Kehidupan dalam Cerpen/Novel Beserta Contohnya (online) diakses dari sekolah (sekolahbagiilmu.blogspot.com/2017/12/12-nilaikehidupan-dalam-cerpennovel.html?m=1) dikunjungi Senin, 10 Agustus 2020

Unknow. 2012. Teori Pendekatan Dan Metode Analisis Sastra Pragmatik (online) diakses dari andiacg.blogspot.com/2012/01/bab-i-pendahuluan.html?m=1) dikunjungi Kamis, 25 Juni2020 